\title{
La hidra revolucionaria. Apocalipsis y antiliberalismo en la España del primer tercio del siglo XIX*
}

\author{
Francisco Javier Ramón Solans ${ }^{1}$ \\ University of Münster \\ ramonsol@uni-muenster.de
}

RESUMEN: El objetivo de este artículo es analizar cómo se recurrió al universo profético apocalíptico para interpretar los acontecimientos del convulso período 1793-1825. Para ello, se han trabajado fundamentalmente obras de inspiración profética y prensa de la época. Al poner en diálogo estas fuentes con los acontecimientos que interpretaban hemos buscado recuperar la historicidad de estos documentos, observar las nuevas formas y medios con los que se expresa el discurso profético y destacar su importancia para comprender cómo fueron percibidos los cambios políticos y culturales. Para abordar estas cuestiones, el artículo se centra en cuatro aspectos que ponen de relieve la evolución del discurso profético en el periodo analizado: los discursos apocalípticos en torno a Napoleón, las profecias sobre la restauración del orden, las profecías antiliberales $y$, finalmente, los peligros que planteaban las profecías para la Iglesia. En este artículo hemos podido ver cómo el marco profético formó parte de la cultura política católica de inspiración anti-liberal. La profecía no sólo sirvió para interpretar los acontecimientos políticos sino para combatir al enemigo político.

\section{Palabras clave: Profecía; Apocalipsis; Antiliberalismo; Iglesia ca- tólica; Napoleón; Guerra de la Independencia.}

* Este trabajo ha sido posible gracias al apoyo de los proyectos de investigación del Ministerio de Economía, Industria y Competitividad titulado «Restauración y monarquía en los orígenes del mundo contemporáneo. España y Europa, 1814-1848» (HAR2012-32604), dirigido por Pedro Rújula, y «Representaciones de la historia en la España contemporánea: políticas del pasado y narrativas de la nación (1808-2012)» (HAR2012-31926), dirigido por Ignacio Peiró.

${ }^{1}$ ORCID iD: http//orcid.org/0000-0001-8667-3553. 
The Counterrevolutionary Hydra. Apocalypse and anti-liberalism in Spain in the first third of XIXth Century

ABSTRACT: The aim of this paper is to analyze how prophecy and Apocalypse were used to interpret the events of the tumultuous period of 1793-1825. To that end, I have worked mainly with prophetic books and press. By putting in dialogue these sources with the events they interpreted, I have sought to recover the historicity of these documents to analyze the new ways they are expressed and to stress the significance of these documents to understand how political and cultural changes were perceived. To address these issues, the article focuses on four aspects showing the evolution of prophetic speeches in this period: the apocalyptic discourses about Napoleon, the prophecies looking for the restoration of the Old Regime, the anti-liberal prophecies and, finally, the dangers of prophecies for the Church. In this paper I have showed that the prophetic framework was part of the anti-liberal catholic political culture. The prophecy not only interpreted political events but also to fight the political enemy.

KeY WORDS: Prophecy; Apocalypse; Anti-liberalism; Catholic Church; Napoleon; Peninsular War.

CÓMO CITAR ESTE ARTÍCULO/CITATION: Ramón Solans, Francisco Javier, «La hidra revolucionaria. Apocalipsis y antiliberalismo en la España del primer tercio del siglo XIX», Hispania, 77/256 (Madrid, 2017): 471-496. doi: 103989/hispania.2017.014.

Desvanecidas las ensoñaciones del progreso y la secularización, los siglos XVIII y XIX aparecen hoy bajo una luz muy distinta. La época de la Ilustración se nos muestra más bien como una centuria de lo irracional, cuyos ecos proféticos, lejos de apagarse, se amplificaron en un Ottocento que contraponía apariciones marianas de un fuerte contenido profético a los grandes descubrimientos científicos. Esta inclinación por lo sobrenatural adoptó las más diversas formas, desde la mística iluminista de Martínez de Pasqually, Johann Kaspar Lavater o Louis Claude de Saint Martin hasta el socialismo utópico de Owen; desde los poemas de William Blake a la pintura de Füssli o Goya; desde el mesmerismo al espiritismo; desde las convulsionarias y las beatas hasta el despertar profético que sacudió las sociedades europeas y anglosajonas en la era de las revoluciones ${ }^{2}$. Todos estos casos evidencian una fascinación por lo oculto y lo trascendental, una búsqueda mística, más allá de los límites de la razón, del significado del pasado, el presente y el futuro.

En la era de las revoluciones, la aceleración del tiempo histórico y la apertura del horizonte de expectativas hizo proliferar discursos de carácter profé-

2 Un balance de esta variedad de manifestaciones en RAMON SOLANS, 71/2 (París, 2016). 
tico $^{3}$. En sus pioneros trabajos de historia de las emociones, Georges Lefebvre señalaba que este período histórico se caracterizó esencialmente por dos emociones interrelacionadas y contrapuestas: el miedo y la esperanza. Ambos sentimientos, producidos por la crisis o promesa revolucionaria, conducirían también a un despertar milenarista ${ }^{4}$. En lo esencial, el marco de referencia de este despertar profético fue cristiano, basado en los libros proféticos del Antiguo Testamento y, sobre todo, en el Apocalipsis. Tanto la inestabilidad producida por el cambio político como la desaparición de referentes hicieron que el catolicismo apareciera como un eficaz y flexible marco interpretativo de los acontecimientos políticos.

En España, esta efervescencia profética tuvo un carácter eminentemente contrarrevolucionario, abundando referencias de carácter apocalíptico al presente político del momento ${ }^{5}$. En este artículo intentaremos dar cuenta de cómo se recurrió al universo profético para interpretar los acontecimientos del convulso período 1793-1825. El principal objetivo de este texto es recuperar la historicidad del propio discurso profético, analizando su naturaleza híbrida y porosa en constante diálogo con los acontecimientos ${ }^{6}$. Asimismo, también reflexionaremos sobre el rol y las formas que adquirieron dichos discursos en la incipiente esfera pública y la densificación de la política del universo popu$\operatorname{lar}^{7}$. Finalmente, ofreceremos una reflexión sobre los problemas que planteaba la profecía para la institución eclesiástica a través de la polémica en torno a la obra del jesuita chileno Manuel Lacunza.

\section{LA LLEGADA DEL DRAGON DEL APOCALIPSIS}

Y apareció otra señal en el cielo: un gran dragón rojo, con siete cabezas y diez cuernos, y sobre sus cabezas siete diademas. Su cola arrastra la tercera parte de las estrellas del cielo y las precipitó sobre la tierra.

Apocalipsis, cap. 12, vers. 3-4

Con la Guerra de la Convención (1793-1795), la Revolución francesa traspasaba las fronteras españolas. Los sermones y otros textos religiosos anun-

3 Para las relaciones entre la profecía y la aceleración del tiempo, ver ESCUDIER, 64/6, París, 2009:1269-1301.

4 VOVELLE, 1992: 29-44 y LEFEVRE, 1998. Un balance sobre la historia de las emociones en DELUERMOZ, FUREIX, MAZUREL y OUALDI, 47, París, 2003: 155-189.

5 Para la profecía en la España en este período ver CID, Madrid, 2014: 179-207 ; RAMON SOLANS, 28, Madrid, 2012: 215-243 ; RAMON SOLANS, 96/4, Madrid, 2014: 83104 y RAMON SOLANS, $2015:$ 45-62 .

6 Para la historicidad del discurso profético, véase RAMON SOLANS, 71/2, París, 2016.

7 RUJULA, 2011: 173-190. 
ciaban la venida de la temida hidra revolucionaria. De hecho, en los prolegómenos del conflicto, el padre escolapio Fray Tomás de San José ya había avisado a sus parroquianos contras los peligros de la Bestia, «cerremos los oídos a los venenosos silbos del Dragón infernal, que después de haber arrojado del Cielo de la Iglesia con su maldita cola la tercera parte de las estrellas, todavía se embravece contra las restantes $\rangle^{8}$. Al poco de estallar la guerra, el obispo de Santander, Rafael Tomás Menéndez de Luarca precavía de una manera muy similar a sus feligreses cuando les advertía contra el «monstruo de la libertad francesa», un dragón «muy cercano pariente del llamado en el Apocalipsis, Draco magnus» ${ }^{9}$-. Así, en estos primeros textos, observamos uno de los elementos más repetidos en los discursos proféticos de este período: la comparación del enemigo con el dragón de siete cabezas que aparecía en el capítulo 12 del Apocalipsis.

A diferencia de las profecías de la Guerra de la Independencia, en estos textos la Bestia es representada como un todo amorfo, una turbamulta, caracterizada con rasgos animales. En su famoso manual para el soldado católico, Fray Diego José de Cádiz nos hablaba de este monstruo disforme, para lo que hacía referencia a otro de los grandes clásicos del discurso profético, el libro de Daniel:

Las sectas más escandalosas, las herejías más perversas, y los más crasos errores pueden mirarse como unas pequeñas sabandijas, si con estas fieras se comparan, de tal suerte, que todas ellas juntas, aun no son bastante para darnos una completa idea de este monstruo el más disforme. La malicia, el desorden y la generalidad de sus desatinadas leyes y preceptos incomparablemente a todas les excede. No de otra suerte, que aquella cuarta bestia, que se manifestó en visión al santo Daniel, que excedía en crueldad, en fuerza y en poder a las otras tres, que antecedentemente se le habían manifestado ${ }^{10}$.

En su Historia de la vida del hombre (1794), el jesuita exiliado Lorenzo Hervás y Panduro incidía en esta identificación colectiva de la Revolución con el Anticristo, señalando que éste se encontraba ya entre nosotros y no era otro que el partido de los filósofos que:

manda en Francia, y públicamente promueve el ateísmo como religión nacional de los franceses, los cuales han desterrado de sus estados el catolicismo, negando a Jesucristo, y negándole la divinidad, han verificado parte de las profecías, que san

8 SAN JOSE, 1793: 32. Aunque todavía no se conociera la ejecución del rey, este texto es una buena muestra del paso de una retórica anti-ilustrada a una contrarrevolucionaria. Para el tránsito de la anti-ilustración a la contrarrevolución ver MCMAHON, 2005.

9 MENÉNDEZ DE LUARCA, 1794: CLXXXII-CLXXXII.

10 CADIZ, 1795: 5. 
Juan inspirado de divina revelación dejó registradas en sus Epístolas y en el Apocalipsis. En aquella nos dice, que el Antecristo estaba ya en el mundo; y que Antecristo era el que negaba la divinidad a Jesucristo ${ }^{11}$.

Poco después, en su célebre ensayo sobre las Causas de la Revolución francesa, que circulaba ya de manera manuscrita en la Roma de 1795 y que fue publicado en 1807, Lorenzo Hervás y Panduro analizaba la Revolución Francesa como una serie de figuras que anunciaban la llegada del Apocalipsis. El figurismo consistía en interpretar un acontecimiento como la promesa de otro que se realizaría completamente en el futuro y con el que no existía relación causal o temporal. Aunque este sistema interpretativo fuera utilizado mayoritariamente por los jansenistas, también estuvo muy presente en la cultura jesuítica y, en general, en la cultura cristiana que había sido capaz de releer el Antiguo Testamento como una serie de figuras que anunciaban la llegada de Jesucristo ${ }^{12}$.

Así, para Lorenzo Hervás y Panduro, entre la persecución francesa y la del Anticristo, existe la «correspondencia que hay entre el eco y la voz que lo forma: entre el precursor que figura, y el figurado» ${ }^{13}$. Salvo por el hecho de que en esta ocasión los príncipes protestantes se han unido con los católicos en su lucha contra la Revolución,

en todo lo demás hallaremos que la actual persecución francesa de la religión cristiana es una de las más visibles precursoras, que hasta ahora ha habido de la gran persecución que contra la misma religión hará el Anticristo [...] La persecución romana del cristianismo por los tres siglos primeros de la iglesia, y la aparición y los progresos del mahometismo con inmensos desastres del cristianismo son los dos sucesos acaecidos, que más claramente se descubren en el Apocalipsis anunciados y ya verificados; y el presente de la Revolución Francesa es el más que hasta ahora ha acaecido para darnos a conocer el carácter de la persecución, que contra la iglesia moverá el Anticristo. [...] debo hacer las siguientes observaciones, con que expongo hallarse entre la persecución francesa, y la del Anticristo la correspondencia que hay entre el eco y la voz que lo forma: entre el precursor que figura, y el figurado ${ }^{14}$.

Así, el jesuita español se lanzaba a analizar todos los rasgos de la Revolución Francesa que pudieran prefigurar la llegada del Apocalipsis. En primer lugar, al igual que los siervos de la Bestia llevan el número 666 como distin-

11 HERVAS, 1794: 141.

12 Para el figurismo jansenita, véase MAIRE, 63/1 (París, 2008): 7-36 y MAIRE, 10 (París, 1996): 28-47. Para la interpretación figurista dentro del cristianismo, véase AUERBACH, 1998.

13 HERVAS, 1807, vol. 1: 30.

14 HERVAS, 1807, vol. 1: 29. 
tivo de irreligión, los franceses portan «el gorro o bonete de la libertad absoluta en materia de religión y de gobierno». Esta señal, también la «ponen en sus plazas y calles, simbolizándola con el árbol de la libertad que en ellas enarbolan: y con el nombre libertad, que escriben en las fachadas de sus casas» ${ }^{15}$. Asimismo, la Convención francesa portaría el nombre del Anticristo por haber negado el nombre de Cristo, si bien

no se ha hecho adorar en el templo, como lo hará el Anticristo, más en él ha hecho adorar un símbolo suyo, que lo es de toda sensualidad y vicio [...] El pueblo francés por símbolo de la naturaleza, que confesaba su divinidad, se propuso y adoró a una joven ramera que simbolizase la deshonestidad, y toda sensualidad ${ }^{16}$.

Con todo, los discursos apocalípticos generados tras la guerra de la Convención no llegarían a alcanzar la difusión o la importancia que tuvieron los que se dieron durante la Guerra de la Independencia. Frente a un conflicto limitado tanto en intensidad como extensión (no llegó a afectar a ninguna gran ciudad), la invasión napoleónica de 1808 llegó hasta el último rincón de la península y alcanzó unos niveles inéditos de destrucción y de violencia contra la población civil. Las estructuras políticas, sociales y económicas del Antiguo Régimen se vieron profundamente sacudidas por la invasión napoleónica.

La Guerra de la Independencia fue un conflicto de naturaleza poliédrica, ya que fue al mismo tiempo, internacional y civil, reacción xenófoba contra los franceses y revuelta contrarrevolucionaria ${ }^{17}$. Para una buena parte de los españoles que tomaron las armas en 1808 ésta era además una «guerra de religión», una «cruzada» contra la impiedad ${ }^{18}$. El miedo que producía la llegada de las tropas francesas generó una ola de milagros por toda la geografía española ${ }^{19}$. Las imágenes apocalípticas promovidas desde la época de la guerra de la Convención habían contribuido a fijar este terror en el imaginario de los españoles. Ante la cercanía de las tropas francesas, los llamamientos a la resistencia también adquirieron tintes apocalípticos, como si del último combate entre el bien y el mal se tratara. Con ello se pretendía «desvelar» los oscuros propósitos de unos enemigos que se presentaban bajo la bandera de la libertad y así movilizar a los españoles contra el invasor. El 6 de junio de 1808, el Diario de Valencia equiparaba a Napoleón con Apolión, ángel del abismo que lideraba el ejército de langostas en el Apocalipsis:

15 HERVAS, 1807, vol. 1: 33.

16 HERVAS, 1807, vol. 1: 38-39.

17 ALVAREZ JUNCO, 12, Salamanca, 1994: 75-99.

18 Este modelo interpretativo ha sido analizado entre otros por ALONSO, 2008: 77.

19 RAMON SOLANS, 96/4, Madrid, 2014: 83-104. 
Conoce España, que [tú, Napoleón] mientes cuanto hablas, que engañas a cuantos tratas, que tu sed de sangre humana es insaciable; y que eres aquel rey inicuo que tenían sobre si las miserables langostas, que significa a los héroes que vio san Juan, y se llamaría Apolión, que es lo mismo que exterminador. Conoce que eres un verdugo que ha enviado Dios al mundo para castigarle ${ }^{20}$.

Este tipo de discursos, cargados de referentes apocalípticos, se concentraron principalmente entre la primera retirada de los ejércitos napoleónicos tras la batalla de Bailén y la entrada de la Grande Armée en noviembre de 1808. Los textos se caracterizan por el optimismo y una cierta alegría, situándose en el plano del final del reinado de la Bestia y el reinado de mil años de Cristo en la tierra. Además, este tipo de discursos se caracterizan por personificar las referencias apocalípticas en la figura de Napoleón. Durante la Guerra de la Independencia el sujeto de este tipo de discursos escatológicos no va a ser pues la muchedumbre revolucionaria sino el emperador francés como encarnación del Anticristo o el Leopardo del Apocalipsis ${ }^{21}$. El carácter diabólico de Napoleón se vio reforzado en contraposición al mito del «príncipe inocente», objeto de persecución por el malvado Godoy y luego de engaño por parte de Napoleón ${ }^{22}$.

Para rastrear los paralelismos entre el Anticristo y Bonaparte, estos textos adoptaron la forma de exégesis o comentario bíblico de capítulos del Apocalipsis. Los autores daban rienda suelta a su imaginación para establecer una comparación entre el presente y el libro de la Biblia analizado. Así, por ejemplo, el misionero Gregorio López preparó una versión en verso del capítulo IX del Apocalipsis de san Juan que el receptor de Cruzada, Juan de Dios Doblado, anotaría e introduciría. Según el autor del prólogo, la propia invasión de los franceses estaba registrada en el Apocalipsis:

Coteje el lector la Divina Escritura con el suceso, y verá pintada por el Evangelista la incursión con tan vivos colores, que no dejan entrada a la duda: las señas características de los enemigos, sus armas ofensivas y defensivas; sus robos; su impiedad; sus hechos; el nombre expreso de su Soberano con carácter inhumano; y el tiempo preciso que prefijo el Señor a la Persecución [...] No deja arbitrio para dudar que habló el Santo terminantemente del acaecimiento de nuestra España ${ }^{23}$.

20 Demostración de la lealtad española: colección de proclamas, bandos, ordenes, discursos, estados de ejército y relaciones de batallas publicadas por las juntas de gobierno o por algunos particulares en las actuales circunstancias. Tomo Primero, Madrid, Imprenta de Repullés, 1808, p. 70.

21 Para la imagen de Napoleón como el Anticristo véase TULARD, 1965: 12-13 y, más recientemente, PETITEAU, 2004: 25-51. Para el uso de estas imágenes durante la Guerra de la Independencia, ver ALONSO, 2008: 91-93; FRASER, 2006: 310 y ETIENVRE, 1998: 32.

22 LA PARRA, 2007: 225-226.

23 DOBLADO, 1808: 4-5. 
En ocasiones, bastaba una simple semejanza en la pronunciación de su nombre para establecer paralelismos con el Apocalipsis. Así, Juan de Dios Doblado fundaba una de uno de los pilares de su argumentación en que es «tan corta la variación que hay de Napoleón, a Apolión» ${ }^{24}$. En el Diario de Mallorca aparecía un análisis muy similar en el que se señalaba como

El doloso Napoleón (o Zapo-León) nos ha robado a Fernando VII aquel iris de
paz en quién la nación entera había colocado sus más lisonjeras esperanzas [...]
Añádase a esto, que para adelantar sus detestables proyectos, nos ha enviado a
un ejército de monstruos, cuales nos los describió san Juan en su Apocalipsis
(cap. 9) cuando dijo: que iban vestidos con corazas, como corazas de hierro [...]
que el ruido de sus alas era como el ruido de los carros de muchos caballos que
corren al combate [...] que sus colas parecían a las de los escorpiones, y en estas
colas tenían aguijones para dañar a los hombres, por espacio de cinco meses [...]
En fin ellas tenían por caudillo a un rey ángel del abismo, llamado en hebreo
Abaddon, en griego Apollyon (nótese la semejanza del nombre) y en latín exter-
minador ${ }^{25}$.

Los comentarios proféticos escritos en el otoño de 1808 son una buena muestra del optimismo que produjo la derrota de Bailén y la retirada de los ejércitos franceses entre los españoles. Esta euforia se tradujo en profecías que señalaban que el reinado de la Bestia había pasado. Juan de Dios Doblado señalaba que ya habían pasado aquellos temibles cinco meses, «que anunció el Santo duraría la persecución» y que fue el tiempo «que prefijó la sabía providencia debiendo reconocer que sin un particular auxilio de la divina mano de Dios, era imposible librarnos del tirano usurpador por la indolencia en que yacía la patria» ${ }^{26}$. Así, si los españoles volvían a la religión y el orden, se salvarían de la vuelta de la bestia.

Probablemente el ejemplo más elaborado de este tipo de textos sería el libro La bestia de siete cabezas y diez cuernos o Napoleón emperador de los franceses. Exposición literal del capitulo XIII del Apocalipsis (1808). Para demostrar la cercanía del fin de los tiempos, su autor, un anónimo cura malagueño analizaba el capítulo XIII del Apocalipsis subrayando las semejanzas entre Napoleón y la Bestia (p. ej. ambas salieron del mar, Córcega y tenían «siete cabezas y diez astas, y sobre las astas diez coronas» en referencia a los territorios que poseía el emperador en Europa) ${ }^{27}$. Minuciosamente, iba haciendo coincidir, frase a frase, las profecías de san Juan con la vida de Napoleón e incluso realizaba cálculos en función de la virtud numeral de las le-

24 DOBLADO, 1808: 21.

25 Diario de Mallorca, 3 de Noviembre de 1808.

26 DOBLADO, 1808: 5 y 19.

27 ANONIMO, 1808a: 3. 
tras griegas para hacer que el nombre del emperador diera como resultado el número de la bestia: $666^{28}$.

El texto estaba marcado por un cierto optimismo ya que en junio de 1808 se habían cumplido cuarenta y dos meses de su reinado (desde su coronación en diciembre de 1804), «el tiempo señalado por la divina Providencia a su tiránico poder y crueles triunfos: $\mathrm{y}$ en efecto desde aquel tiempo cesaron sus victorias» ${ }^{29}$. Sin embargo, se prevenía al lector contra la relajación ya que «nuestros pecados pueden dilatar su castigo, y nuestra escandalosa impenitencia hacernos participantes de las horribles penas que están ya decretadas contra él» $\gg^{30}$.

En el Despertador Christiano-Político (1808), Simón López, eclesiástico y diputado por Murcia a las Cortes de Cádiz interpretaba también las cabezas y cuernos de la Bestia como los territorios que poseía Napoleón. Al igual que en el texto anónimo, se habla del emperador como el leopardo del Apocalipsis que es capaz de camuflarse y esconder sus verdaderas intenciones bajo apariencia pacífica ${ }^{31}$. Para el futuro Arzobispo de Valencia, el emperador francés:

es el leopardo del Apocalipsis, que toma todas las figuras y colores que le acomodan para engañar y dominar: él es finalmente la bestia horrenda de siete cabezas y diez cuernos, salida del mar y autorizada con toda la potestad infernal, sentada sobre muchas aguas, esto es, muchos pueblos, naciones y lenguas que ha señoreado con su política diabólica, y los hace servir a sus malditos intentos ${ }^{32}$.

Sin embargo, Simón López no se muestra tan cauto como el cura malagueño. Ya no había vuelta atrás, la resistencia española «animada de la Religión, de la confianza en Dios y devoción a la Virgen y amor a su legítimo Soberano» había supuesto la caída de Napoleón, y de «la grande ramera, la misteriosa Babilonia, la París amada, madre de cismas, apostasías y herejías, que ha hecho prevaricar a casi toda Europa» ${ }^{33}$.

Las referencias al Anticristo se multiplicaron durante aquel año de 1808 e incluso se utilizaron para intentar hacer desistir a los franceses de la causa del emperador y ayudar a los españoles a restaurar las legítimas dinastías europeas:

28 Un análisis más detallado en RAMÓN SOLANS, 28, Madrid, 2012: 215-243. Este texto tuvo bastante difusión en la época e incluso fue traducido en 1809 al portugués. A besta de sete cabeças e dez cornos ou Napoleão, imperador dos franceses. Exposição litteral do capitulo XIII do Apocalypse, por hum presbytero andaluz, visinho da cidade de Malaga, Lisboa, Of. Joaquim Thomaz de Aquino Bulhões, 1809.

29 ANONIMO, 1808a: 7.

30 ANONIMO, 1808a: 20-21.

31 LÓPEZ, 1808: 1. Este texto también tuvo bastante difusión y se hizo una edición mejicana en 1809.

32 LÓPEZ, 1808: 3-4.

33 LÓPEZ, 1808: XXVIII-XXIX. 


\begin{abstract}
No apartéis de vuestra memoria el combate de Wamba en el Rosellón. Acordaos de Roncesvalles, de Pavía y de Fuenterrabía. No os hago estos recuerdos por arrogancia, y sí para que conozcáis vuestro estado, vuestro peligro, y la constitución en que os ha colocado vuestro Emperador; sí ese monstruo de maldad, ese hombre de pecado, figura del Antecristo; y que unidos a la nación española, vuestra amiga, borréis el nombre y dinastía de ese usurpador, y os limpiéis la mancha con que ha descolorido vuestra conducta, sacudáis su infame y vergonzoso yugo, y aspiremos todos juntos a la gloria de ver restablecida en Francia una monarquía legítima nacional, la religión católica y el carácter formal con que os han distinguido las demás naciones ${ }^{34}$.
\end{abstract}

La asociación entre la figura del emperador francés y el Anticristo fue tan exitosa que, en algunos momentos, llegaron a inducir en la población la idea de que el fin de los tiempos estaba cerca. Este fue el caso del pánico que produjo en la diócesis de Granada la llegada del 15 de agosto de 1813, onomástica de Napoleón y fecha en la que se iba a producir el fin del mundo según un rumor bastante difundido en la región ${ }^{35}$.

Asimismo, como ha estudiado Gabriel Cid, este es un discurso que traspasa las fronteras de la península y afecta de lleno al mundo hispánico. Napoleón aparecería como uno de los «jinetes del Apocalipsis» según el dominico mexicano Luis Carrasco y Enciso o como el «dragón escarlata de siete cabezas» para el eclesiástico neogranadino Rafael Lasso de la Vega. Además, en 1811 se edita por primera vez la Venida del Mesías en Gloria y Majestad, manuscrito del jesuita Manuel Lacunza (1731-1801). El texto de Lacunza se planteó como una respuesta a las críticas anticristianas de la Ilustración, vinculando el deísmo con la cuarta bestia descrita por el profeta Daniel ${ }^{36}$. En España, este libro va a tener una favorable acogida por la mencionada necesidad de interpretar y dotar de significados los acontecimientos de la Guerra de la Independencia. La obra sorprende además por su favorable recepción no sólo en círculos contrarrevolucionarios sino también entre jansenistas por sus críticas al papado y medios judíos por el carácter filosemita de su mesianismo ${ }^{37}$.

\title{
Profetizar El REgReso
}

La apertura del futuro también estuvo marcada por una ansiosa búsqueda de la restauración del pasado. De esta manera, la profecía se conjuga como un

34 ANONIMO, 1808b: 152-153.

35 GUTIERREZ, 1814.

36 CID, 133 (Madrid, 2014): 179-207.

37 MARTINEZ, 3 (Colombia, 1990). Además en esta época también se traduce otro opúsculo que sitúa el fin del mundo en 1860, Carta de un canónigo a un amigo, sobre la proximidad del fin del mundo: Impresa en Fermo año de 1797; traducida al castellano, Coruña, Antonio Rodríguez, 1813. 
tiempo compuesto, como un futuro cargado de pasado. Acontecimientos como la ejecución de Luis XVI, la muerte en prisión de Pio VI o la detención de Pio VII y Fernando VII generaron un gran desconcierto en una parte de la población y alimentaron esta coyuntura apocalíptica ${ }^{38}$. Se multiplicaron los rumores de todo tipo que proyectaban en el inmediato futuro la tan ansiada restauración de la normalidad. En algunos casos se afirmaba que no habían muerto, como el caso del regreso de los «falsos Luis XVII» durante el reinado de Luis XVIII. Así, según las profecías que proliferaron en la Francia de la Restauración, el joven Delfín no sólo no habría muerto en prisión en 1795 sino que volvía para restaurar el orden y la religión. Durante aquellos años, encontramos incluso a varias personas que decían ser los legítimos herederos al trono de Francia y que gozaron de una gran popularidad. Este fenómeno de los «falsos Luis XVII» sería una respuesta a la inestabilidad política y el descontento producido por las frustradas esperanzas en el nuevo rey ${ }^{39}$.

Otros creyeron haberse reunido con el Papa durante su exilio como la profetisa sor Rosa María Jesús quién, según su relato, tras haber recibido una visión de Dios, habría acudido a Savona para comunicársela a Pio VII. El Pontífice le habría confirmado en su misión y le habría encargado felicitar a los buenos prelados, amenazar a los malos y «tomar todos los medios que me parezcan convenientes hasta conseguir la paz de la Iglesia» ${ }^{40}$. Nada queda de esta reunión más que el inverosímil testimonio de sor Rosa María en el que no se da ningún tipo de detalles de cómo se produjo dicho encuentro ni cómo superó la vigilancia napoleónica.

En esta restauración soñada del orden del Antiguo Régimen no podían faltar las profecías en torno al restablecimiento de la Compañía de Jesús. Desde 1770, una joven campesina italiana, Bernardina Renzi, y una religiosa dominica, María Teresa del Cuore di Gesù, comenzaron a profetizar la muerte de Clemente XIV, el castigo de los responsables de la supresión de la Compañía de Jesús y su restablecimiento bajo la protección de un gran emperador. A pesar de ser reprimidas, sus profecías gozaron de gran predicamento entre los círculos de ex-jesuitas ${ }^{41}$.

En esta misma línea estaría el caso de la profetisa francesa la señora Bouche que, tras iniciarse en el círculo iluminista de Aviñón con el conde polaco

38 A pesar de que pudiera existir una cierta ruptura afectiva con la monarquía, en los albores de la crisis del Antiguo Régimen, los reyes seguían siendo contemplados a través de imágenes paternales que les descargaban de toda responsabilidad en los polémicas que les afectaban. El rey era el buen padre rodeado de malos y corruptos consejeros. CHARTIER, 2000: 173 .

39 BOUTRY y NASSIF, 1985 y AIRIAU, 39 (París, 2009): 115-127.

40 JESUS, 1811: 9.

41 CAFFIERO, 1991. 
Grabrianka y el benedictino Pernety, se habría decantado por la causa del Papa gracias a la influencia del ex-jesuita, Ferrier de Chivas. La señora Bouche habría intentado convencer a las «cabezas más importantes del Universo» (el Papa, el Rey de Francia, el Rey de España y el Emperador de Rusia) de la necesidad de restaurar la Compañía de Jesús para frenar las funestas doctrinas y los crímenes que asolaban el planeta. La señora Bouche mantuvo contactos con Carlos IV durante su exilio e intentó sin éxito entrevistarse con el Papa en Savona. No tuvo tampoco mejor suerte con Napoleón, al que escribió en dos ocasiones, ni con Luis XVIII. Según los informes del fondo de policía francesa, en 1819, finalmente consiguió atraer la atención del duque Eugen de Württemberg, tío del zar Alejandro, que le dio 1200 francos y un pasaporte ruso para acudir a la corte de San Petersburgo ${ }^{42}$.

Los jesuitas españoles habían visto en la llegada al trono de José Bonaparte un castigo por los pecados de Carlos III y Carlos IV. El 25 de julio de 1808, festividad de Santiago, pidieron en Roma al apóstol patrón de la monarquía y nación española que la liberase de «caer en las manos de los impíos ateístas franceses». En este contexto y a diferencia de las profecías que señalaban la restauración de la compañía como el medio más adecuado para vencer a la Bestia, el ex-jesuita Manuel Luengo señalaba como ésta se produciría más bien como un premio por la victoria de la religión sobre el Anticristo ${ }^{43}$.

La prisión de Fernando VII, el rey que tantas esperanzas había despertado, causó también desasosiego entre la población. Desde la primavera de 1808, Fernando VII fue presentado como un «nuevo David», la reencarnación de los reyes bíblicos, «como así confirmaban una serie de "auspicios" o características únicas de su persona $)^{44}$. Su ausencia del trono había generado todo tipo de rumores y leyendas. Tan sólo dos días antes del levantamiento del 2 de mayo, un boletín informaba de que Fernando VII se había casado con una princesa Bonaparte y estaba ya de regreso a España. La noticia generó un gran regocijo en la población madrileña que salió a la calle a celebrarla. Sin embargo, cuando ésta fue desmentida al día siguiente se produjo el efecto contrario y reinó entre la población una gran conmoción y desconcierto ${ }^{45}$.

En el México insurgente, corrieron numerosos rumores en torno a la presencia de Fernando VII en Nueva España. Se decía que iba con una máscara de plata acompañando a Hidalgo en contra de las autoridades coloniales o que los ingleses lo habían liberado y llevado a México, dónde encabezaría una

42 Archivo Nacional de Francia, F7, Caja 6971, dossier 12785

43 GIMENEZ LÓPEZ Y FERNANDEZ ARRILAGA, 2010: 18-19.

44 ALONSO, 14, Alicante, 2015: 60. Su regreso en 1814 fue visto e instrumentalizado como obra de la Providencia y por tanto, el monarca sería presentado como un monarca enviado por Dios. LA PARRA, 17 (León, 2014): 39-53.

45 FRASER, 2006 : 63-64. 
rebelión contra los capuchinos. Estos rumores sobre la presencia del rey en América fueron analizados por Eric Van Young como una manifestación de un milenarismo primitivo, en la línea de lo expuesto por Eric Hobsbawm. Sin embargo, este uso por los insurgentes mejicanos parece responder más bien, como señala Marco Antonio Landavazu, a un deseo popular de que el rey se instalara en el trono de América. Aunque puedan parecer sorprendentes, estas aspiraciones fueron canalizadas tanto para romper como para reforzar vínculos con la metrópolit6. En España, estas aspiraciones al retorno del monarca sirvieron también a la postre para dos proyectos políticos totalmente diferentes: romper con el Antiguo Régimen o restaurarlo.

Aunque en la Península Ibérica no se produjeron fenómenos equiparables a los de México o Francia, en 1808 se publicó un texto con connotaciones proféticas, un sueño anónimo titulado Religiosas víctimas inmoladas en el corazón de la España. El autor o autora de esta fantasía despertaba en el preciso momento en el que se producía una sangrienta invasión y era incapaz de reaccionar ya que se sentía congelado por el miedo. Entonces se le aparecía el Tiempo, representado por un señor mayor, para criticarle la inacción de los habitantes ante esa horrorosa situación y anunciarle

escuchad a mi voz la profecía que quizá ya sabéis, un rey esclavo y de aflicción cubierto, restaurará su cetro y su grandeza destruirá la Francia, y hará se olvide del fasto de la historia, hasta el nombre francés... Dijo, y de mi vista desapareció dejándome lleno de admiración y espanto: y todo electrizado, en tan justas y ciertas expresiones, exagerado mi natural quietud abandonando, me puse en pie, empuñé el acero, a mi patria, al pueblo y a la corte mi colérica faz preponderando de esta manera hablé ${ }^{47}$.

\section{DE NAPOLEÓN AL LIBERALISMO}

Conforme avanza la Guerra de Independencia y sobre todo, a partir de la derrota de Napoleón, la Bestia apocalíptica deja progresivamente de identificarse con el emperador francés. Así, por ejemplo, para evitar que se vivieran escenas de terror como las de la onomástica de Napoleón en Granada, el editor de El Amigo de los Sabios o ilustración literaria dedicaba un número de la revista a mostrar que «en Napoleón no concurren las cualidades que se han expresado del Anticristo» y que se aproxima más a figuras como Pilatos o Judas Iscariote. Napoleón iba a ser derrotado como se verificó con Nabucodonosor, Antíoco, y «con otros muchos que buscando revoluciones y grandes

46 LANDAVAZO, $2001:$ 166-168. VAN YOUNG, $1992: 420$.

47 ANONIMO, 1808c: 19. 
señoríos fueron del todo abatidos, perseguidos y muertos, y de sus reinos y vastos imperios despojados $\rangle^{48}$.

Al mismo tiempo, la publicística contrarrevolucionaria comenzó a identificar la Bestia con los liberales. El Anticristo dejó de estar personificado en el emperador para pasar de nuevo a ser una masa informe y terrible de filósofos y revolucionarios. En la versión ampliada del Diccionario razonado, manual para inteligencia de ciertos escritores que por equivocación han nacido en España se señalaba que «en la biblia filosófica no hay salmos porque falta el supuesto: ni profetas porque no hay Mesías prometido ni cumplido; ni Apocalipsis porque ya no es una cosa futura ${ }^{49}$. En la voz dedicada al Apocalipsis el diccionario incidía sobre esta idea de que gracias a los liberales el fin de los tiempos era ya una triste realidad ${ }^{50}$.

Al mismo tiempo, para desacreditar a los liberales se les acusaba de ser falsos profetas, una acusación que entroncaba con aquellas que contra los iluminados se habían vertido ante el Santo Oficio. Fray Antonio Miguel Yuramí criticaba a aquellos «que gloriándose del nombre de cristianos, quieren ser tenidos por profetas, y aun iluminados por Cristo, pero que en realidad son herejes» que quieren acabar con la religión ${ }^{51}$. En la prensa encontramos referencias similares cuándo se hablaba de los diputados en el Congreso como aquellos «que sin milagros que autoricen su extraordinaria misión, se han erigido en profetas, en maestros y nos quieren enseñar las verdades, que tan útiles han sido a nuestros vecinos, y cuyas consecuencias pesan tanto sobre nuestras cabezas» ${ }^{52}$. En una carta al Procurador General del Rey y de la Nación se distinguía a los verdaderos profetas, los contrarrevolucionarios, de los falsos profetas, los liberales:
en todos tiempos ha habido profetas falsos y profetas verdaderos. Durante la glo- riosa revolución de España, han sido los falsos, los redactores generales, los duen- des, los concisos, los diarios mercantiles y los demás insectos de esta infernal cala- ña. Los profetas verdaderos son los procuradores generales, los atalayas, los sensatos, las estafetas de Santiago, los filósofos rancios y de antaño. Ya que V. profetizó tan bien en orden a la dichosa venida del mejor Rey ${ }^{53}$.

La profecía se adentró también en los nuevos espacios que la guerra de ideas estaba abriendo como se puede apreciar en las profecías de sor Rosa María de Jesús, monja del convento de recoletas de Salamanca, que viajó a

48 GUTIERREZ, 1814: 14.

49 ANONIMO, 1811: 14.

50 ANONIMO, 1811: 12.

51 YURAMI, 1813: 3.

52 El Sensato, 6 de febrero de 1812.

53 El Procurador General del Rey y de la Nación, 14 de agosto de 1814. 
Cádiz para tratar de convencer a las Cortes de su misión divina. En su opinión, para vencer a Napoleón era necesario que se instalara la religión de las Siervas de María Santísima de los Dolores, que la Virgen fuera nombrada generalísima del Ejército y que se celebrara un ayuno general de tres días con rogativas públicas con el objeto de desagraviar a Dios por la supresión de la Compañía. La cuestión llegó a debatirse en Cortes y la Comisión eclesiástica para la celebración de un Concilio nacional, dirigida por el clérigo liberal Joaquín Lorenzo Villanueva, tuvo que realizar un informe sobre la petición de sor Rosa María de Jesús ${ }^{54}$. Pronto los liberales se dieron cuenta del potencial contrarrevolucionario de dicha monja y en la prensa aparecieron diversos artículos en los que se señalaba que «mejor estás con el Trifauce cerbero, que nosotros con el censor general, la M. Rosa, el P. Alvarado, el Abate Provisor» ${ }^{55}$.

Al igual que ocurrió con los discursos apocalípticos sobre Napoleón, las referencias al liberalismo se concentraron en un tiempo triunfal para la causa realista, el regreso de Fernando VII y la restauración del Absolutismo. Las profecías parecían buscar la confirmación de una victoria que todavía no consideraban como segura. Así, en junio de 1814 una carta dirigida al Procurador General del Rey y de la Nación invitaba a seguir alertas ante las conspiraciones liberales:

\begin{abstract}
Parece que experimentamos aquella terrible catástrofe prevenida por san Juan en el cap. 12, v. 12 del Apocalipsis [...] Ay de vosotros tierra y mar, porque ha bajado a vosotros el diablo, teniendo grande ira, sabiendo que le queda poco tiempo. Nunca señores editores, se vio el Rey en mayor peligro, nunca sus vasallos fieles se vieron más al canto de perderse por la malignidad de los satélites de Lucifer, que ahora que la Iglesia de Jesucristo se eleva triunfante sobre las olas de la irreligión, que la bestia infernal vomitó como un río caudaloso que salía de su boca para ahogarla si pudiera. Ahora son más refinadas sus intrigas, más autorizada su desesperación para destruir a los cristianos más acrisolados ${ }^{56}$.
\end{abstract}

De igual manera, durante el Trienio liberal no abundaron los discursos apocalípticos y hubo que esperar a otro tiempo de victoria para los contrarrevolucionarios, la década ominosa, para encontrar referencias al fin de los tiempos. En 1824 encontramos un género propagandístico sumamente interesante, las cartas de un liberal arrepentido a su confesor. La primera epístola está cargada de referencias apocalípticas y comienza reconociendo que «yo he sido liberal, filosofo y revolucionario; ipluguiese a Dios que no lo hubiese sido! He erigido altares al monstruo, y he sacrificado víctimas a este numen

54 Para sor Rosa María de Jesús ver RAMON SOLANS, 2015.

55 Gazeta de Madrid, $\mathrm{n}^{\circ}$ 6, 6 de enero de 1812, p. 24.

56 El Procurador General del Rey y de la Nación, 23 de junio de 1814. 
sanguinario» ${ }^{57}$. A continuación, el liberal convertido recurría al Apocalipsis de San Juan y al Libro de Job para describir aquel monstruo infame:

el filosofismo liberal, que es sin duda el más temible de los monstruos, no puede describirse mejor, que comparándole con aquel Leviatán del que nos dice el Libro de Job (cap. 41) Su estornudo es resplandor de fuego, y sus ojos, como las pestañas de la aurora. De su boca salen hachas, como teas de fuego encendidas. De sus narices sale humo como de olla encendida e hirviente. Su aliento hace encender los carbones, y de su boca sale llama. En su cuello hará asiento la fortaleza, y delante de él va el hambre. O bien con aquella bestia que vio san Juan en la isla de Pathmos (Apocalip. Cap. 3 v. 2) semejante a un leopardo cuyos pies eran de oso, y tenía una boca como la boca de un león ${ }^{58}$.

Al igual que había hecho la publicística apocalíptica con Napoleón, nuestro liberal arrepentido traza un paralelismo entre la Bestia de siete cabezas del Apocalipsis y un Liberalismo, cuyas principales cabezas «se apellidan materialismo, soberanía popular y libertad de imprenta: una se llama jacobinis$m o$, y es la que tiene asolada a la Francia; otra radical, que actualmente conmueve a la Inglaterra; la Italia, Nápoles y el Piamonte deben sus revoluciones a la carbonaria, así como la España y Portugal deben también las suyas a la llamada liberal» ${ }^{59}$.

Sin embargo, el autor de estas cartas no se limita a las referencias bíblicas y se nutre de todo tipo de fuentes para que el lector pueda imaginarse los horrores del liberalismo. Así, se dejaba llevar por la fantasía y comparaba a los liberales con el volcán del Vesubio, el Cancerbero o las serpientes del Orinoco. Al final, como si de un bestiario se tratara, el autor diseccionaba a la bestia liberal para desvelar sus intenciones:

Sus cuernos, que así llamo a sus perversas intenciones, son como los del toro, que sacan las tripas al infeliz que aprehenden; y semejante a las harpías de la fábula, ensucia cuanto toca con sus uñas y su pico: corre como los gamos, pues que la más ágil política apenas lo alcanza; repta como las culebras, pues que ninguno de sus pensamientos se levanta de la tierra; nada como los peces, pues que del continente pasa a las Islas, y de Cádiz a las Américas: y vuela como las aves, pues que con indecible ligereza se transporta de uno a otro reino ${ }^{60}$.

De esta manera, los referentes religiosos-apocalípticos se mezclan con otros provenientes de la naturaleza o del mundo clásico ${ }^{61}$. Sin embargo, ni

57 ANONIMO, 1824: 5.

58 ANONIMO, 1824: 6-7.

59 ANONIMO, 1824: 10.

60 ANONIMO, 1824: 11.

61 Véase GARCIA MONERRIS y GARCIA MONERRIS, 10, Alicante, 2011: 150. 
siquiera la naturaleza es capaz de dar cuenta de este horror, puesto que el liberalismo, no se conforma con sus leyes, y es «en todo diferente de los animales, engendra con dolores y pare con placeres; goza de una fecundidad tan grande que raya a lo infinito: es ovíparo y vivíparo; y por tanto, no es extraño que se multipliquen tanto sus hijos, los que son todos bastardos, negros, astutos, orgullosos y malignos» ${ }^{62}$. Sin embargo, ya no hay razones para temer dicha bestia, «porque los leales y valerosos realistas, esos Hércules y Teseos de nuestra España lo han mortalmente herido, que está casi agonizando» ${ }^{63}$.

Al igual que otros textos de la época, esta carta vinculaba los orígenes del liberalismo con el protestantismo, la filosofía y el jansenismo. Sin embargo, la principal novedad en este sentido radica en el hecho de situar el origen de la «Bestia» en Norteamérica y, más precisamente, en el movimiento de los cuáqueros. Así, a pesar de que el monstruo carece de Patria ya que es «cosmopolita», el autor se basa en el célebre texto del Apocalipsis para afirmar que la Bestia nació más allá de los mares y que fue de allí, de dónde pasó «a la Francia de donde vino después a España» para cruzar de nuevo el Atlántico y llegar a la América española ${ }^{64}$. El autor no explica las razones que le llevan a afirmar ese origen cuáquero de la Revolución y parece más bien que nos encontramos ante un recurso retórico para excitar la imaginación del lector, recalcar el carácter extraordinario del liberalismo y exculpar a Francia en parte de la Revolución, tan sólo un año después de la famosa expedición francesa de los Cien mil hijos de San Luis.

\section{LOS PELIGROS DE LA PROFECÍA}

Sin embargo, dentro de la Iglesia se alzaban voces contra los excesos producidos por esta cultura profética. Las autoridades eclesiásticas no se sentían cómodas ante unos discursos que no siempre podían controlar con facilidad y que corrían el riesgo de deslizarse por terrenos inesperados ${ }^{65}$. Por ello, en algunos casos, se mantiene una actitud ambigua sino hostil hacia este tipo de discursos y figuras carismáticas. En este sentido cabría destacar cómo durante el siglo XIX la Iglesia tuvo que hacer frente a una efervescencia devocional (apariciones marianas, milagros, etc.) que se acompañaba de discursos en los que se mezclaba profetismo, escatología y catolicismo intransigente. A primera vista, esta mezcla parecía ligar perfectamente como ocurrió en las apariciones marianas de la Salette (1846), en la que la Virgen aparece llorando por

\footnotetext{
62 ANONIMO, 1824: 10.

63 ANONIMO, 1824: 13.

64 ANONIMO, 1824: 31.

65 ESCUDIER, 64/6 (París, 2009) : 1291.
} 
la impiedad de los nuevos tiempos y amenaza con grandes castigos si esta situación no revierte. Sin embargo, esta combinación de profecía y catolicismo intransigente no fue vista siempre con agrado desde el Vaticano y la Congregación de la Romana y Universal Inquisición se encargó de podar las ramas que podían tener derivas más inesperadas y peligrosas ${ }^{66}$.

En el período que analizamos, estas prevenciones de la Iglesia con la profecía se observan perfectamente en las respuestas a la mencionada obra del jesuita chileno Manuel Lacunza. Como ya se ha señalado, La Venida del Mesías es una obra que tuvo una amplia y variada acogida, que iba desde sectores más próximos al liberalismo hasta la contrarrevolucionaria Petite Église y los círculos anticoncordatarios lioneses ${ }^{67}$. El éxito de esta obra fue tal que, antes de su impresión, ya se podían conseguir en Roma en 1794 versiones manuscritas en latín e italiano. Pronto aparecerían versiones en inglés, francés o español ${ }^{68}$.

Desde la recién restaurada Compañía de Jesús se siguió con especial preocupación la difusión de una obra que podía perjudicar profundamente la imagen todavía precaria de la orden. A finales de 1818, el Obispo de Calahorra, Anastasio Puyal, le escribía al rector del Colegio de Loyola, Faustino Arévalo, señalando que la obra había sido publicada antes del restablecimiento de la Compañía y con la desaprobación de sus superiores. Además, señalaba con preocupación la difusión que estaba alcanzando la obra

en Madrid se habla mucho de ella ahora y que los enemigos meten ruido con esta ocasión y se ha esparcido la voz de que saldrá condenada en el primer Edicto que se publicará de la Inquisición. La suponen impresa en Sevilla (yo creo lo que V. me decía que se había impreso en Gibraltar) y que por Andalucía se había despachado toda la impresión ${ }^{69}$.

La extraordinaria difusión de esta obra llamaría la atención del Santo Oficio español. El Inquisidor General y obispo de Tarazona, Gerónimo Castillón, señalaba cómo

La naturaleza de esta obra y de las materias que en ella se tratan en nuestro idioma, su introducción y publicación clandestinas con manifiesta infracción de las leyes civiles y eclesiásticas; la estudiada reserva con que se vende y circula furtivamente, y la perturbación y ansiedades que su lectura ha causado en los ánimos de muchos sabios e ignorantes, alarmaron el celo de nuestro ministerio ${ }^{70}$.

66 MULTON, 621, París, 2002: 109-137. Para la dimensión apocalíptica de La Salette ver ANGELIER y LANGLOIS, 1996.

67 CHANTIN, 1998: 61.

68 Las primeras ediciones en España de este libro son de 1811, 1812 y 1815. ZABALLA, 11, Pamplona, 2002: 115-128.

69 Carta citada en ZABALLA, 11, Pamplona, 2002: 119.

70 Diario del Gobierno de la Habana, 27 de septiembre de 1819. 
El 15 de enero de 1819, Gerónimo Castillón prohibió provisionalmente que se vendiera, leyera e incluso poseyera en cualquiera de los idiomas en que se había publicado hasta que fuera examinada minuciosamente por teólogos so pena de 200 ducados y excomunión. La dureza de esta prohibición respondía al hecho de que hasta que llegara el juicio del Santo Oficio, «la lectura de dicha obra puede producir y produce escándalos y divisiones, con tendencia a una guerra de opiniones religiosas». La Venida del Mesías, según el Edicto de la Inquisición, «ha llegado a haberse introducido en estos reinos primeramente manuscrita y después impresa en lengua vulgar sin lugar ni año de impresión y sin las competentes licencias de las respectivas autoridades (...) aunque en la portada dice, con superior permiso, por D. Felipe Tolosa impresor de la ciudad» ${ }^{71}$.

Durante el Trienio liberal, la publicación de la obra de Lacunza alcanzó una gran celebridad. A pesar de que había sido impresa en varias ocasiones, todavía circulaba en forma manuscrita, lo que es una buena prueba del éxito que gozaba así como de la variedad de formas en que se transmitía ${ }^{72}$. Además, la propia publicación fue objeto de acusaciones cruzadas entre los contrarrevolucionarios y liberales sobre la responsabilidad de la obra. Así, como vimos durante la Guerra de la Independencia, la profecía se adentraba en los nuevos terrenos de la esfera pública de la mano de las polémicas periodísticas.

En su periódico Defensa cristiana católica de la Constitución novísima de España, el padre vallisoletano y apologeta contrarrevolucionario Josef Ventura Martínez se sorprendía por el eco que había tenido la obra de Lacunza, un libro que usaba los textos de la divina Escritura «cuando acomodan a su intento y recurriendo a la metáfora por sola su voluntad, cuándo contradicen su sistema» y por ello, pensaba que:

una tal obra no merecería sino la execración de los cristianos. Pero habiendo entendido que se lee, aunque clandestinamente y que un cierto teólogo, que podrá tener su poco de autoridad entre los que no le conocen, y que dice, y ha dicho en muchas partes, y entre quienes no le podían replicar, que se había tenido por feliz en haber leído aquella obra, en la que decía haber encontrado la clave para entender el apocalipsis, y nada contrario al catolicismo ${ }^{73}$.

Desde el liberalismo también se realizaron condenas a una obra que consideraban como parte de una conspiración de la «pandilla jesuítica». Así, en $E l$

71 Diario del Gobierno de la Habana, 27 de septiembre de 1819.

72 Así, en el Diario de Madrid se informaba de la pérdida de un manuscrito de la Venida del Mesías en la calle de la Magdalena y se ofrecía una recompensa para aquel que lo encontrara. Diario de Madrid, 14 de marzo de 1822.

73 Defensa cristiana católica de la Constitución novísima de España, 31 de marzo de 1821. Sobre el padre Martínez, REVUELTA GONZALEZ, 1973: 113-114. 
Universal, se señalaba que «como tenemos casualmente algún conocimiento de esta singular producción y bastantes noticias de su historia secreta» informamos «sobre un libro que reputamos por peligroso y nocivo». El libro habría sido publicado al final de la Guerra de la Independencia y durante los seis años de poder absoluto para «alimentar la falsa devoción, introducir la superstición y sugerir el fanatismo». Así, «el verdadero objeto de esta obra es fomentar una especie de misticismo, a qué los jesuitas y sus secuaces han sido siempre muy inclinados, y por cuyo medio intentan ahora estos últimos recobrar alguna parte de su perdida dominación sobre las conciencias de los fieles». Además se refutaba el contenido por sus similitudes con el joaquinismo y su promesa de la llegada de la era del Evangelio eterno ${ }^{74}$.

Con la restauración del absolutismo, el franciscano mallorquín Juan Buenaventura Bestard escribió un completo tratado en dos volúmenes para rebatir la obra de Manuel Lacunza. El texto es una buena muestra de la creciente actitud hostil de una parte de la Iglesia contra las dimensiones que estaba adquiriendo el fenómeno profético. Bestard precavía a la población, advirtiéndoles del «cuidado que tuvo el Señor de instruirnos y armarnos contra la seducción de aquellos pseudo Cristos y pseudo-Profetas, que apoyando en fingidos milagros y prodigios su falsa predicación, clamarán en los últimos tiempos: ecce hic est Christus aut illio» ${ }^{75}$. Asimismo, el padre Bestard confirmaba la extraordinaria difusión que tuvo el texto de Lacunza, que «llegó manuscrita por desgracia a esta península, y comenzó a hacer sus prosélitos, habiéndolos ya hecho antes en Italia y otras partes». El propio Bestard había visto la obra manuscrita en 1802 en poder del teniente general de la Real Armada, Francisco Gil Lemos y en Latín en la Habana en 1814 «en poder de un eclesiástico ejemplar, que la había conseguido así en Italia» ${ }^{76}$.

Al poco de publicarse el primer volumen del libro de Bestard, el 6 de septiembre de 1824, la obra de Lacunza fue oficialmente incluida en el índice de libros prohibidos junto con otras publicaciones entre las que destacarían dos obras del eclesiástico Juan Antonio Llorente. En el Diario Balear se hacían eco de esta noticia y se lamentaban de que fueran «la mayor parte españolas y fruto desdichado de la revolución ${ }^{77}$. Tras la condena oficial del Tribunal del Santo Oficio romano, el padre Bestard publicaría un segundo volumen que incluiría una carta del Nuncio Santiago Giustiniani en el que le informaba de que León XII le daba «las más expresivas gracias por su fina atención, alabando mucho que se ocupe en una cosa tan digna y en el modo en que lo hace» ${ }^{78}$. La conde-

74 El Universal, 25 de enero de 1823.

75 BESTARD, 1824, vol. I: 3.

76 BESTARD, 1824, vol. I: 5.

77 Diario Balear, 23 de diciembre de 1824.

78 BESTARD, 1825, vol. II. 
na oficial de la obra de Lacunza así como la favorable carta del Papa hicieron que el libro de Bestard fuera muy bien acogido por el público ${ }^{79}$.

Las repetidas condenas de la obra de Lacunza así como las continuas referencias a su circulación clandestina, tanto en forma manuscrita como impresa, son síntomas del profundo anclaje de la cultura profética en la población a comienzos de la época contemporánea. Asimismo, las reacciones ante la obra de Lacunza nos muestran la versatilidad de las profecías a la hora de apoyar causas políticas diversas y la creciente preocupación de la Iglesia ante las dimensiones que estaba adquiriendo dicho fenómeno profético a comienzos del siglo XIX.

\section{CONCLUSIONES}

Durante el primer tercio del siglo XIX, el Apocalipsis fue utilizado para interpretar la crisis del Antiguo Régimen y el nacimiento de nuevas formas políticas en España. Así, en este artículo hemos podido ver cómo el marco interpretativo profético formó parte de la cultura política católica de inspiración anti-liberal. Sin embargo, esto no quiere decir que el universo profético fuera un simple e inmutable repertorio al que recurrir en coyunturas de crisis. Al devolver a la profecía su historicidad, observamos como estos discursos están en constante cambio, evolucionando junto con los acontecimientos que interpretan. En función de estos, el tono del discurso alterna entre el optimismo y el pesimismo. Bajo una apariencia inmutable, la profecía adquiere nuevas formas y se adentra en terrenos inexplorados, participando de los nuevos códigos de discusión en la esfera pública, siendo presentada a las Cortes o publicitada en diarios.

Las referencias apocalípticas se modifican a lo largo del período. Así se pasa de las descripciones que hablan de aquella masa informe y salvaje del ejército revolucionario como parte de la Bestia de siete cabezas a la progresiva identificación del Anticristo con la figura de Napoleón durante la Guerra de la Independencia. Conforme avanza el conflicto y las tropas francesas son derrotadas, el emperador francés cederá su puesto a un colectivo informe, pérfido, maquiavélico e intrigante, los liberales. Por su parte, el tiempo de la profecía se concentra en períodos de victoria para la contrarrevolución como la primera retirada francesa tras la derrota de Bailén o la restauración del absolutismo en 1814. Las referencias apocalípticas, contrariamente a lo que podríamos pensar, se producen mayoritariamente tras experimentar los horrores de la guerra, como una suerte de confirmación de la tan anhelada victoria.

79 Diario de avisos de Madrid, 21 de febrero de 1826 y Diario Balear, 17 de marzo de 1826. 
Quedaría por responder si el uso de figuras apocalípticas implica una verdadera creencia en la cercanía del final de los tiempos. La pregunta no es sencilla de contestar. Desde luego en algunas ocasiones, las referencias al Apocalipsis parecen ser un recurso narrativo para hacer que el lector se imagine la maldad de sus enemigos, o precisamente para todo lo contrario, para que los sitúe en el terreno de los miedos más terribles, aquellos que no podemos si quiera llegar a imaginar ${ }^{80}$. Sin embargo, por lo general, su utilización parece responder a una sincera creencia en la cercanía del final de los tiempos. Las comparaciones y análisis minuciosos de la vida de Napoleón y del Anticristo muestran un uso que va más allá del simple recurso a las figuras apocalípticas y refleja una preocupación por descifrar los acontecimientos del presente en dicha clave. Asimismo, los fenómenos de miedo colectivo, así como el éxito de obras como la de Lacunza, muestran el profundo impacto de estas profecías en la población.

Finalmente, encontramos cómo la profecía y los discursos apocalípticos generan problemas en el seno de la Iglesia, ya que son discursos que escapan a su control y que pueden tener derivas inesperadas e indeseadas. De esta manera, la Iglesia mantiene una actitud ambigua frente a estos discursos y, con la reafirmación del poder papal en el siglo XIX, se intentará desarrollar un control cada vez más estricto de ellos. No obstante, su aceptación o rechazo dependerán de una gran cantidad de variables que van desde la situación local de la Iglesia hasta la política vaticana. De hecho, conforme avanza el siglo, se promoverá un cierto tipo de visiones vinculada con apariciones marianas y con connotaciones intransigentes. Las profecías evolucionaron al compás de los tiempos que interpretaban.

\section{FUENTES PRIMARIAS}

Anónimo, La bestia de siete cabezas y diez cuernos o Napoleón emperador de los franceses. Exposición literal del capítulo XIII del Apocalipsis, Málaga, Imprenta de Martínez, 1808a.

Anónimo, «Manifiesto a los franceses que compendia los primeros acontecimientos de su revolución y los hechos más notables con que han sido tiranizados por su Emperador Napoleón», en Colección de papeles interesantes sobre las circunstancias presentes, $\mathrm{n}^{\circ} 12,1808 \mathrm{~b}$.

Anónimo, Religiosas víctimas inmoladas en el corazón de la España, por la restauración y felicidad de su perseguido monarca el señor Don Fernando el VII (que Dios guarde), s.l., s.f., 1808.

Anónimo, Diccionario razonado, manual para inteligencia de ciertos escritores que por equivocación han nacido en España. Aumentado con más de cincuenta voces

80 BAUMAN, $2007: 10$. 
y una receta eficacísima para matar insectos filosóficos, Cádiz, Imprenta de la Junta Superior, 1811.

Anónimo, El monstruo más deforme, más feroz y venenoso que han visto jamás los siglos: descrito por un liberal desengañado. Carta del liberal arrepentido a su confesor. $\mathrm{N}^{\mathrm{o}}$ 1, Tortosa, Imprenta de Joaquin Puigrubí, 1824.

Bestard, Juan Buenaventura Observaciones que ... presenta al público, para precaverle de la seducción que pudiera ocasionarle la obra intitulada: la venida del mesías en gloria y majestad de Juan Josaphat Benezra, Cuaderno Primero. Vol. 1, Madrid, Imprenta de D. Fermín Villalpando, 1824.

Bestard, Juan Buenaventura Observaciones que ... presenta al público, para precaverle de la seducción que pudiera ocasionarle la obra intitulada: la venida del mesías en gloria y majestad de Juan Josaphat Benezra, Cuaderno Primero. Vol. 2, Madrid, Imprenta de D. Miguel de Burgos, 1825.

Cádiz, Diego José de, El soldado católico en guerra de religión. Segunda Parte, Barcelona, Juan Francisco Piferrer, 1795.

Doblado, Juan de Dios, Exposición del capitulo IX del Apocalipsis de San Juan, aplicándolo según su sentido literal al extraordinario acontecimiento de la pérfida irrupción de España por los franceses en el año de 1808, en una oda, con notas que aclaran la letra, s.1., Imprenta de Ruiz, 1808.

Gutiérrez, Alfonso, El amigo de los sabios o ilustración literaria. Quaderno $n^{\circ} 6$, Granada, Imprenta de Don Manuel Moreno, 1814

Hervás y Panduro, Lorenzo, Causas de la Revolución de Francia en el año de 1789, y medios de que se han valido para efectuarla los enemigos de la religión y del estado. Tomo I, Madrid, s.n., 1807.

Hervás y Panduro, Lorenzo, Historia de la vida del hombre. Tomo III. Parte II, Madrid, Imprenta Real, 1794.

Jesús, Rosa María de, Viage de la M. Rosa María de Jesús a ver a N.S.P. Pío Séptimo, y tratar con su santidad de la paz de la Iglesia, y libertad de la Nación Española, Cádiz, 1811.

López, Simón, Despertador Christiano-Político en que se manifiesta que los autores del trastorno universal de la Iglesia y de la Monarquía son los filósofos FrancMasones: se descubren las artes diabólicas de que se valen y se apuntan los medios de atajar sus progresos, Murcia, Viuda de Muñiz e Hijo, s.a. [1808].

Menéndez Luarca, Rafael Tomás, El Reino de Dios y su Justicia, obradora de la paz de Cristo, príncipe de la paz. Exhortación que el obispo de Santander hacía a sus diocesanos y por ellos a todos los Españoles, sobre guerrear, Fuertes en la Fe, las Guerras del Señor contra sus enemigos los Franceses libres, Santander, 1794.

San José, Tomás de, Sermón de la Purificación de la Virgen que en el día 2 de febrero de 1793 dijo en la Santa Iglesia Metropolitana del Pilar de Zaragoza, Zaragoza, Mariano Miedes, 1793.

Yuramí, Antonio Miguel Demostración de las falsedades y calumnias con que pretende desacreditar a las religiones el autor del papel intitulado Sevilla libre, Sevilla, Viuda de Vázquez, 1813. 


\section{BIBLIOGRAFÍA}

Airiau, Paul, «La légitimité incertaine (1814-1853): retour sur les faux Louis XVII», Revue d'histoire du XIXe siècle, 39 (París, 2009): 115-127

Alonso, Gregorio, «"Del Altar una barricada, del santuario una fortaleza": 1808 y la nación católica», en Joaquín Álvarez Barrientos (ed.), La Guerra de la Independencia en la cultura española, Madrid, Siglo XXI, 2008: 75-103

Alonso, Gregorio, «Imaginando a Fernando VII, rey católico y felón», Pasado y Memoria, 14 (Alicante, 2015): 57-77.

Álvarez Junco, José, «La invención de la Guerra de la Independencia», Studia historica. Historia contemporánea, 12 (Salamanca, 1994): 75-99.

Angelier, François y Langlois, Claude (eds.), La Salette. Apocalypse, pèlerinage et littérature (1846-1996), Actes du colloque de l'institut catholique de Paris (2930 de novembre de 1996), Grenoble, Jérôme Million, 2000.

Auerbach, Eric, Figura, Madrid, Trotta, 1998.

Bauman, Zygmunt Miedo líquido. La sociedad contemporánea y sus temores, Paidós, Barcelona, 2007.

Boutry, Philippe et Nassif, Jacques, Martin l'Archange, París, Gallimard, 1985.

Caffiero, Marina, La nuova era : miti e profezie dell'Italia in rivoluzione, Genova, Marietti, 1991.

Chantin, Jean-Pierre, Les Amis de l'Euvre de la Vérité ; jansénisme, miracles et fin du monde au XIX siècle, Presses Universitaires de Lyon, 1998.

Chartier, Roger, Les origines culturelles de la Révolution française, Paris, Seuil, 2000.

Cid, Gabriel, «"Las señales de los últimos tiempos”. Laicidad y escatología en el pensamiento católico hispanoamericano del siglo XIX», Hispania Sacra, 133 (Madrid, 2014): 179-207

Deluermoz, Quentin; Fureix, Emmanuel; Mazurel, Hervé; et Oualdi, M'hamed, «Écrire l'histoire des émotions: de l'objet à la catégorie d'analyse », Revue d'histoire du XIXe siècle, 47 (París, 2003): 155-189.

Escudier, Alexandre, «"Temporalisation” et modernité politique : penser avec Koselleck », Annales. Histoire, Sciences Sociales, 64/6, (París, 2009): 1269-1301.

Etienvre, Françoise, «Introducción», a Antonio Campmany, Centinela contra franceses, Madrid, Támesis Books, 1988: 11-73.

Fraser, Ronald, La maldita guerra de España. Historia social de la Guerra de la Independencia. 1808-1814, Barcelona, Crítica, 2006.

García Monerris, Encarna y García Monerris, Carmen, «Palabras en guerra. La experiencia revolucionaria y el lenguaje de la reacción», Pasado y Memoria, 10 (Alicante, 2011): 139-162.

Giménez López, Enrique y Fernández Arrillaga, Inmaculada «Estudio introductorio » a Manuel Luengo, Diario de 1808: el año de la conspiración, Alicante, Publicaciones de la Universidad de Alicante, 2010: 18-19.

Landavazo, Marco Antonio, La máscara de Fernando VII. Discurso e imaginario monárquicos en una época de crisis. Nueva España, 1808-1812, México, El Colegio de México, 2001. 
La Parra, Emilio, «El mito del rey deseado», en Christian Demange, Pierre Géal, Richard Hocquellet, Stéphane Michonneau y Marie Salgues (eds.), Sombras de mayo. Mitos y memorias de la Guerra de la Independencia en España (18081908), Madrid, Casa de Velázquez, 2007: 221-236.

La Parra, Emilio, «Fernando VII, rey providencial enviado de Dios», Alcores, 17 (León, 2014): 39-53.

Lefebvre, Georges, La Grande Peur de 1789. Suivi de Les foules révolutionnaires, París, Armand Colin, 1988.

Maire, Catherine, «Le figurisme de l'abbé d'Étemare à l'abbé Grégoire », Politica hermetica, 10 (París, 1996): 28-47.

Maire, Catherine, «Les jansénistes et le millénarisme. Du refus à la conversion», Annales. Histoire, Sciences Sociales, 63/1 (París, 2008): 7-36.

Martínez, Fréderic «Milenarismo y defensa de la fe en el Siglo de las Luces: la obra del jesuita chileno Manuel Lacunza», Historia crítica [en línea], 3 (1990). Disponible en http://historiacritica.uniandes.edu.co/view.php/57/index.php?id=57 [consultado el 5 de mayo de 2016].

McMahon, Darrin, Enemies of the Enlightenment. The French CounterEnlightenment and the Making of Modernity, Oxford, Oxford University Press, 2001.

Multon, Hilaire, «Catholicisme intransigeant et culture prophétique: l'apport des Archives du Saint Office et de l'Index», Revue historique, 621 (París, 2002) : 109-137.

Petiteau, Natalie, Napoléon, de la mythologie à l’histoire, París, Seuil, 2004.

Ramón Solans, Francisco Javier, «Conjugando los tiempos presentes. Figuras temporales de la contrarrevolución española (1789-1814)», Historia y Política, 28 (Madrid, 2012): 215-243.

Ramón Solans, Francisco Javier, «Milagros, visiones apocalípticas y profecías. Una lectura sobrenatural de la Guerra de la Independencia », Ayer, 96/4 (Madrid, 2014): 83-104.

Ramón Solans, Francisco Javier, «Una visionaria en las Cortes de Cádiz. Género y profecía en la crisis del Antiguo Régimen», Mercedes Yusta e Ignacio Peiró (coords), Heterodoxas, guerrilleras y ciudadanas. Resistencias femeninas en la España moderna y contemporánea, Zaragoza, Institución «Fernando el Católico», 2015: 45-62.

Ramón Solans, Francisco Javier, «Être immortel à Paris. Violence et prophetie durant la Révolution française», Annales. Histoire, Sciences Sociales, 71/2 (París, 2016): 347-378.

Revuelta González, Manuel, Politica religiosa de los liberales en el siglo XIX, Madrid, CSIC, 1973.

Rújula, Pedro, «Densificación del universo político popular durante la Guerra de la Independencia», Pedro Rújula y Jordi Canal (eds.), Guerra de ideas. Política y cultura en la España de la Guerra de la Independencia, Madrid, Institución «Fernando el Católico»/Marcial Pons, 2011: 173-190. 
Tulard, Jean, L'anti-Napoléon. La légende noire de l'Empereur, París, Fayard, 1965. Van Young, Eric, «El enigma de los reyes: mesianismo y revuelta popular en México, 1880-1815», en La crisis del orden colonial . Estructura agraria y rebeliones populares de la Nueva España, 1750-1821, México, Alianza, 1992: 399-427.

Vovelle, Michel, La découverte de la politique. Géopolitique de la Révolution française, París, La Découverte, 1992.

Zaballa, Ana de, «La Venida del Mesías de Manuel Lacunza. Primeras ediciones y críticas», Anuario de historia de la Iglesia, (Pamplona, 2002): 115-128.

Recibido: $26 / 05 / 2016$

Aprobado: 07/03/2017 